\title{
DESAIN MEJA MAKAN LIPAT \\ UNTUK APARTEMEN PANDAN WANGI TIPE 21
}

\author{
Roni H \\ Staf Pengajar Program Studi Desain Produk, Jurusan Desain \\ Politeknik Negeri Samarinda \\ Ismail \\ Mahasiswa Program Studi Desain Produk, Jurusan Desain \\ Politeknik Negeri Samarinda
}

\begin{abstract}
ABSTRAK
Dapur biasanya menjadi ruangan yang kurang diperhatikan tata letak dan estetikanya, padahal dapur merupakan bagian penting dalam rumah tangga. Tidak semua rumah maupun apartemen memiliki area dapur yang cukup luas. Kondisi dapur seperti ini tidak akan menjadi masalah jika pemilik rumah mampu menyiasatinya dengan baik. Perabotan yang ada di dapur seperti meja makan dapat tertata rapi dan berfungsi ganda untuk mengatasi keterbatasan lahan. Pada meja makan yang sudah ada khususnya di Apartemen Pandan Wangi untuk type 21 belum memilki meja makan dan sebagian besar untuk pengguna apartemen maupun rumah minimalis masih menggunakan meja dengan dimensi yang cukup besar. Meja makan ini tentu sangat menyita ruangan dengan keterbatasan lahan bagi pemilik rumah maupun apartemen. Berdasarkan uraian di atas maka diperlukan sebuah rancangan Meja Makan Lipat Minimalis dengan fungsi utama sebagai meja makan dan dapat dilipat untuk mengatasi keterbatasan lahan pada ruangan sempit atau minimalis. Diharapkan desain meja ini dapat menjadi solusi akan kebutuhan furnitur rumah tangga dengan ruangan yang sempit atau minimalis.
\end{abstract}

Kata kunci: Meja makan, minimalis, apartemen

\begin{abstract}
The kitchen is usually a room that overlooked the layout and aesthetics, but the kitchen is an important part. Not all the houses and apartments have a kitchen area is quite extensive. Conditions in the kitchen like this will not be a problem if the homeowner is able to work around this well. The furniture in the kitchen as a dining table can be neat and doubles to overcome land constraints. At the dinner table that already exists, especially in Apartment Pandan Wangi to type 21 do not have the dining table and most of the apartments and minimalist still use a desk with a large dimension. The dining table is certainly very confiscate the room with limited land for homeowners and apartment. Based on the above it is necessary a Folding Dining Table Minimalist design with a primary function as a dining table and can be folded to overcome the limitations of land in a small room or minimalist. This table design is expected to be a solution to the needs of household furniture with narrow room or minimalist.
\end{abstract}

Keywords: dining table minimalist, apartment 
Roni H, Ismail, Desain Meja Makan Lipat Untuk Apartemen Pandan Wangi Tipe 21

\section{Pendahuluan}

Kebutuhan manusia akan tempat tinggal selalu menjadi kebutuhan utama. Jumlah populasi manusia yang terus bertambah membuat tingkat kebutuhan manusia terhadap tempat tinggal juga terus bertambah. Salah satu solusi yang ditawarkan adalah dengan adanya pembangunan apartemen. Solusi ini dapat diterima oleh kalangan masyrakat. Dalam pembangunan apartemen dibutuhkan perencanaan yang matang dan cermat. Apartemen Pandan Wangi contohnya, merupakan Apartemen yang terletak ditengah kota Samarinda, yang menjadi lokasi penelitian.

Dapur biasanya menjadi ruangan yang kurang diperhatikan tata letak dan estetikanya, padahal dapur merupakan salah satu bagian penting dalam rumah tangga. Tidak semua rumah maupun apartemen memiliki area dapur yang cukup luas. Kondisi dapur seperti ini tidak akan menjadi masalah jika pemilik rumah mampu menyiasatinya dengan baik. Perabotan yang ada di dapur seperti meja makan dapat tertata rapi dan berfungsi ganda untuk mengatasi keterbatasan lahan. Dapur merupakan ruangan privat untuk penggunanya, khususnya untuk ibu rumah tangga. Setiap ibu rumah tangga pasti menginginkan kondisi dapur yang nyaman, sehingga mereka akan berusaha merawat dapur mereka sebaik mungkin.

Pada meja makan yang sudah ada, khususnya di Apartemen Pandan Wangi untuk type 21 belum memilki meja makan 42 dan sebagian besar untuk pengguna apartemen maupun rumah minimalis masih menggunakan meja dengan dimensi yang cukup besar. Meja makan ini menyita ruangan dengan keterbatasan lahan bagi pemilik rumah maupun apartemen.

Berdasarkan uraian di atas maka diperlukan sebuah rancangan Meja Makan Lipat Minimalis dengan fungsi utama sebagai meja makan dan dapat dilipat untuk mengatasi keterbatasan lahan pada ruangan sempit atau minimalis. Diharapkan desain meja ini dapat menjadi solusi akan kebutuhan furnitur rumah tangga dengan ruangan yang sempit atau minimalis.

\section{Metode Perancangan}

Dalam mendesain produk ini dilakukan beberapa tahapan-tahapan agar tersusun proses yang baku, yaitu:

1. Perumusan Masalah. Dengan mendata permasalahan apa yang ada pada produk yang ada saat ini.

2. Tinjauan Pustaka. Yaitu melakukan Studi eksisting yang terdiri dari definisi eksisting beserta jenis dan fasilitas yang diperlukan. Teori segmentasi meliputi segmentasi geografis, segmentasi demografis, segmentasi psikografis, segmentasi prilaku dan segmentasi manfaat. Teori ergonomi dan antropometri untuk pengguna. Teori sistem yang digunakan, Sistem kuncian, sistem sambungan dan sistem finishing. Teori bentuk yang digunakan berdasarkan pendekatan bentuk gaya 
Vol. 3, No. 2, April 2016

desain. Teori warna yang akan digunakan berdasarkan psikologi warna.

3. Analisis dan Spesifikasi Desain, meliputi Analisis pasar, studi aktifitas dan kebutuhan, analisis ergonomi \& antrhopometri, analisis konfigurasi, analisis sistem, analisis material, analisis bentuk, analisis warna dan analisis produksi. Dari hasil analisis ini akan dihasilkan Spesifikasi desain produk.

4. Desain Alternatif. Berupa sketsa beberapa alternatif desain, yang akan dianalisis kelebihan dan kekurangannya, kemudian dipilih menjadi desain terpilih yang akan dikembangkan.

5. Pengembangan Desain Alternatif Terpilih. Yaitu pengembangan dari desain terpilih tahap sebelumnya, menjadi desain final yang siap untuk diproduksi.
6. Desain Akhir. Yaitu finalisasi hasil desain yang bisa dibaca oleh tim produksi sehingga siap diproduksi menjadi produk jadi.

\section{Hasil dan Pembahsan}

Analisis aktivitas dan kebutuhan dilakukan untuk mengetahui aktivitas yang dilakukan berkaitan dengan produk yang akan dibuat sehingga diperoleh kebutuhan pengguna. Berdasarkan kebutuhan tersebut maka dibuat pemecahan untuk memenuhi kebutuhan yang dapat diaplikasikan pada produk. Berikut ini adalah tabel analisis aktivitas dan kebutuhan yang berkaitan dengan produk "Desain Meja Makan Lipat”, yaitu:

Tabel 1. Analisis Studi Aktivitas Dan Kebutuhan

\begin{tabular}{|l|l|l|l|}
\hline No. & Aktivitas & Kebutulnan & Fasilitas \\
\hline 1. & Membuka kuncian & $\begin{array}{l}\text { Kuncian pada meja saat meja } \\
\text { dalam posisi terlipat berupa } \\
\text { magnet. }\end{array}$ & $\begin{array}{l}\text { Mejayang } \\
\text { mempunyaikuncian pada } \\
\text { saat meja tidak digunakan } \\
\text { atau dilipat }\end{array}$ \\
\hline 2. & Makan & $\begin{array}{l}\text { Bidang datar yang seperti papan } \\
\text { untuk melakukan kegiatan makan }\end{array}$ & $\begin{array}{l}\text { Memiliki papan meja } \\
\text { untuk kegunaan makan }\end{array}$ \\
\hline 3. & $\begin{array}{l}\text { Memasang kaki } \\
\text { meja }\end{array}$ & Kaki meja & $\begin{array}{l}\text { Memiliki kaki meja yang } \\
\text { dilipat agar dapat } \\
\text { menopang area datar pada } \\
\text { meja }\end{array}$ \\
\hline 4. & $\begin{array}{l}\text { Mengambil } \\
\text { perlengkapan } \\
\text { makanan }\end{array}$ & $\begin{array}{l}\text { Sebuah rak dibutuhkan untuk } \\
\text { menempatkan perlengkapan } \\
\text { makanan seperti kecap, saus dan } \\
\text { tisu }\end{array}$ & $\begin{array}{l}\text { Rak yang terdapat pada } \\
\text { bagian meja makan lipat }\end{array}$ \\
\hline 4. & $\begin{array}{l}\text { Membuka/melipat } \\
\text { kembali setelah } \\
\text { meja digunakan }\end{array}$ & $\begin{array}{l}\text { Space untuk engsel pada papan } \\
\text { meja ketika dilipat }\end{array}$ & $\begin{array}{l}\text { Memiliki engsel untuk } \\
\text { melipat kembali pada } \\
\text { meja }\end{array}$ \\
\hline 5. & $\begin{array}{l}\text { Menahan meja } \\
\text { ketika digunakan }\end{array}$ & Engsel sikutan dan kaitan & $\begin{array}{l}\text { Memiliki kuncian untuk } \\
\text { menahan meja ketika } \\
\text { digunakan }\end{array}$ \\
\hline 6. & Berkaca & $\begin{array}{l}\text { Kaca yang terdapat pada } \\
\text { meja makan lipat }\end{array}$ \\
\hline
\end{tabular}


Roni H, Ismail, Desain Meja Makan Lipat Untuk Apartemen Pandan Wangi Tipe 21

Setelah menganalisa aktivitas dan kebutuhan pengguna, maka berikut uraian fasilitas yang tersedia pada produk meja makan lipat minimalis yang dirancang: (1) Pada meja yang mempunyai kuncian pada saat meja tidak digunakan atau dilipat, (2) Memiliki engsel pada meja ketika meja dalam posisi terbuka maupun terlipa, (3) Memiliki kaki meja yang dilipat agar dapat menopang area datar pada meja, (4) Memiliki rak untuk meletakan aksesoris pada meja, (5) Memiliki kuncian pada meja saat meja terlipat kembali, (6) Memiliki kaca untuk menjaga penampilan.

Analisis ergonomi dilakukan untuk meminimalkan resiko kesehatan dan keselamatan kenyamanan dalam produk yang dirancang. Dengan begitu efisiensi kesehatan, keselamatan, dan kenyamanan dalam melakukan kegiatan menggunakan produk dapat maksimal.Sedangkan analisis antropometri dilakukan guna mendapatkan dimensi atau ukuran produk yang sesuai dengan tubuh pengguna.

1. Antropometri yang digunakan untuk menentukan panjang meja adalah jarak bentang dari ujung jari tangan kiri ke kanan. Gender yang digunakan adalah wanita. Percentile antropometri yang digunakan untuk wanita adalah 5\%tile yaitu $1.210 \mathrm{~mm}$ ukuran ini menyesuaikan dengan ukuran luas ruangan dan sesuai dengan permintaan pengguna. Untuk ukuran panjang meja keseluruhan terdiri dari bagian daun meja dan lemari rak untuk menempatkan perlengkapan makan, adapun ukuran daun meja adalah $960 \mathrm{~mm}$ dan lemari rak pada meja dengan ukuran $250 \mathrm{~mm}$. Jadi ukuran meja secara keseluruhan panjang meja yaitu $1.250 \mathrm{~mm}$.

2. Antropometri yang digunakan untuk menentukan lebar meja adalah jarak jangkauan tangan kedepan. Gender yang digunakan adalah pria. Jenis antropometri yang digunakan pria adalah 5\% persintil yaitu $649 \mathrm{~mm}$, ukuran percentile tersebut dikurangi dengan toleransi dari tebal pakaian/jaket 49 mm sehingga ukuran lebar meja tersebut adala $600 \mathrm{~mm}$ untuk ukuran maksimal. Dari dimensi jarak jangkauan tangan kedepan maka didapatlah dimensi lebar meja yaitu $600 \mathrm{~mm}$ dengan menggunakan ukuran tubuh pria dewasa.

3. Antropmetri yang digunakan untuk mentukan tinggi meja adalah dimensi antropometri tingi siku pada posisi duduk.Gender yang digunakan adalah pria.Jenis antropometri yang digunakan untuk kelompok pria 5\% persentil, yaitu $750 \mathrm{~mm}$. Dari dimensi jarak tinggi badan pada posisi duduk maka didapatlah dimensi tinggi yaitu 750 mm dengan menggunakan ukuran tubuh pria dewasa.

4. Antropmetri yang digunakan untuk mentukan tinggi rak teratas adalah dimensi antropometri tinggi pegangan tangan pada posisi tangan vertikal ke atas \& duduk. Gender yang digunakan adalah wanita. Jenis antropometri yang digunakan untuk kelompok wanita 95\% 
Vol. 3, No. 2, April 2016

persentil, yaitu $1.330 \mathrm{~mm}$. Dari dimensi

jarak tinggi pegangan tangan pada posisi tangan vertikal ke atas \& duduk maka didapatlah dimensi tinggi yaitu 1.330 mm dengan menggunakan ukuran tubuh pria dewasa.

Analisis konfigurasi yang dilakukan untuk mendapatkan susunan atau konfigurasi dari tiap - tiap komponen yang terdapat pada MejaMakan Lipat Dengan Gaya Minimalis Modern. Berikut adalah gambaran dari konfigurasi produk berserta isinya :
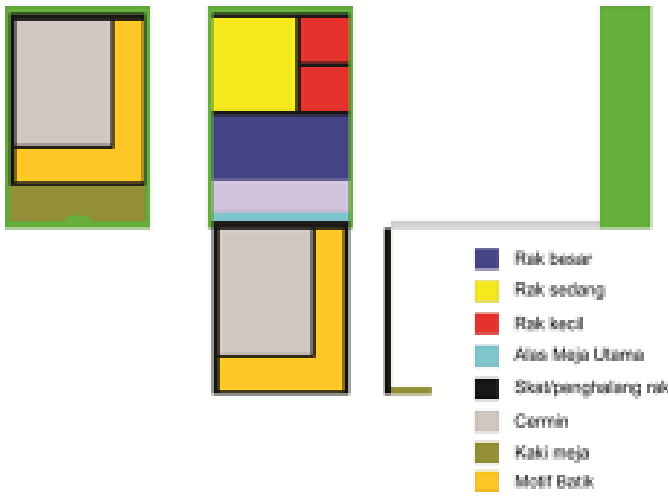

Gambar 1. konfigurasi produk

Pada alternatif konfigurasi, terdapat laci-laci kecil pada bagian bawah sehingga lebih memudahkan saat kita ingin mengambil pelengkap makanan seperti kecap maupun saus dan rak sedang terdapat pada bagian tengah yang dapat digunakan untuk meletakan tisu dan rak bagian atas untuk meletakan aksesoris meja, sedangkan kelemahannya adalah posisi rak besar yang dapat digunakan untuk meletakan aksesoris meja terdapat pada atas meja.
Analisis sistem perlu dilakukan untuk mengetahui sistem-sistem apa saja yang diperlukan pada produk Meja Makan Lipat Dengan Gaya Minimalis Modern tersebut.

Beberapa sistem yang digunakan pada produk:

1. Paku. Sistem sambungan menggunakan paku digunakan untuk menghubungkan komponen-komponen sehingga menjadi sebuah meja.

2. Sekrup. Sekrup digunakan untuk menggabungkan komponen yang besar seperti alas meja dengan dinding meja.

3. Sekrup viser. Sekrup viser digunakan untuk memasang meja makan lipat pada dinding rumah maupun apartemen.

4. Sistem lipat yang digunakan pada produk meja makan ini adalah sistem engsel yang akan diaplikasikan untuk bagian datar meja seperti papan dan kaki meja. Engsel yang digunakan adalah jenis engselpanel,engsel salon (sikutan) dan engsel bracket karena yang dirasa paling cocok untuk digunakan pada meja makan lipat.

Analisis finishing dilakukan guna menentukan pengerjaan akhir pada produk untuk memberikan estetika yang lebih sehinnga memiliki daya jual yang tinggi. Berikut analisis finishing untuk produk Meja Makan Lipat. Dari hasil analisis finishing yang telah dilakukan, nilai yang paling besar dihasilkan oleh finishing menggunakan cat duco. 
Roni H, Ismail, Desain Meja Makan Lipat Untuk Apartemen Pandan Wangi Tipe 21

Analisis yang dilakukan guna menentukan analisis material yang baik yang dapat digunakan pada produk "Desain Meja Makan Lipat Dengan Gaya Minimalis Modern”, sehingga nantinya akan menghasilkan produk yang aman dan nyaman dengan kegiatan pengguna. Dari hasil analisis material yang telah dilakukan, nilai paling besar dihasilkan oleh material kayu jenis multiplek/triplek, sehingga material inilah yang akan dipilih menjadi salah satu material utama untuk membuat meja makan lipat dengan gaya minimalis modern.

Hasil ananlisis bentuk yang dilakukan untuk menentukan gaya desain apa yang sesuai dengan konsep yang akan diaplikasikan pada produk Meja Makan Lipat Dengan Gaya Minimalis Modern. Analisis bentuk dilakukan guna menentukan gaya desain apa yang sesuai dengan konsep yang diambil dan akan diaplikasikan pada produk meja makan lipat. Dari hasil analisis yang dilakukan karena terdapat dua gaya desain diaplikasikan dalam 1 produk maka gaya desain dapat disebut gaya desain Eklektik.

Dari analisis warna yang telah dilakukan guna menentukan warna yang akan diterapkan pada produk meja makan lipat. Analisis warna dilakukan dalam dua jenis, yaitu untuk warna yang mendominasi dan untuk warna yang digunakan sebagai aksen. Warna-warna yang kemungkinan besar akan digunakan adalah warna-warna natural dan warna netral karena meja makan lipatdisesuaikan dengan warna ruang makan.
Warna yang diaplikasikan pada produk meja makan ini kemungkinan besar menggunakan warna natural dan netral. Warna-warna yang digunakan yaitu warna hitam, putih, dan coklat tua. Untuk pemilihan warna hitam pada meja makan lipat akan memberikan kesan gelap dan terlihat berat,sedangkan untuk warna putih memberikan kesan bersih dan untuk warna coklat tua memberikan kesan ruangan menjadi gelap. Dari hasil analisis yang telah dilakukan, maka yang akan digunakan pada meja makan lipat adalah warna putih karena aktivitas makan membutuhkan kesan lingkungan yang bersih.

Langkah awal dalam mengaplikasikan hasil analisis ke dalam produk adalah mendesain awal. Desain awal berupa sketsa-sketsa alternatif desain, kemudian alternatif altenatif tersbut diseleksi sehingga terpilih desain yang memenuhi kriteria. Dari desain terpilih, dikembangkan lagi menjadi beberapa desain pengemabngan, sehingga terwujud desain final. Desain final ini dijabarkan dalam gambar presentasi, gambar isometri, gambar tampak, gambar potongan, gambar urai dan gambar deatil. Desain final dilengkapi dengan spesifikasi teknis, sehingga siap masuk tahap produksi guna diproduksi masal. 


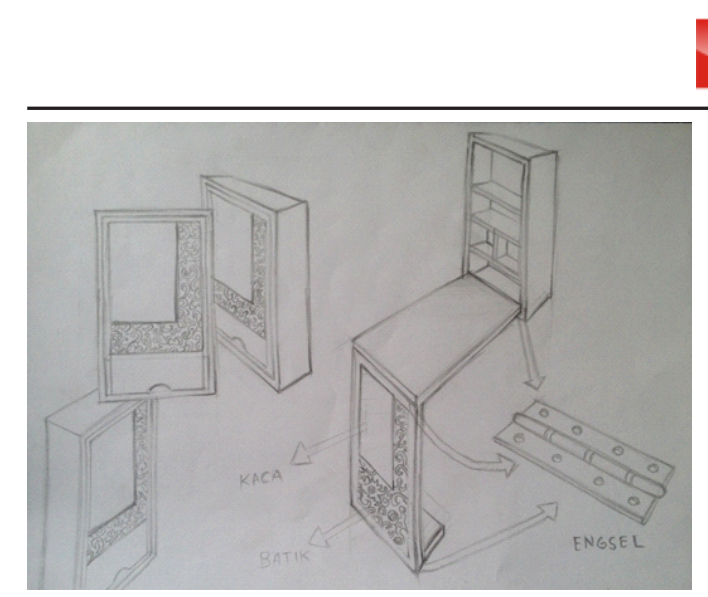

Gambar 2. Desain awal

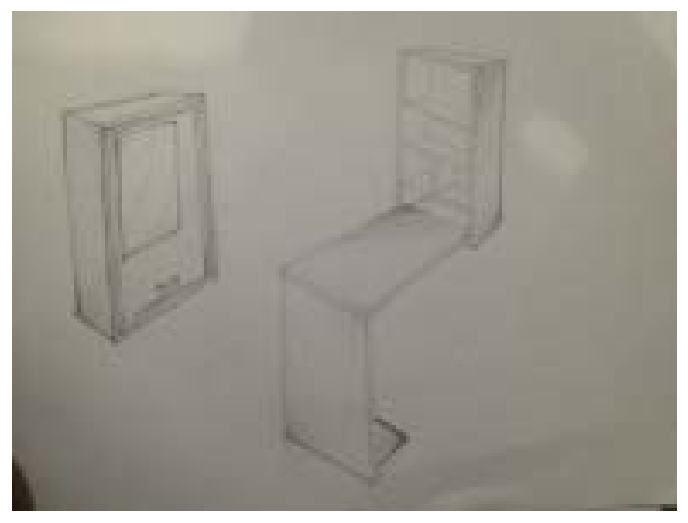

Gambar 3. Pengembangan desain terpilih

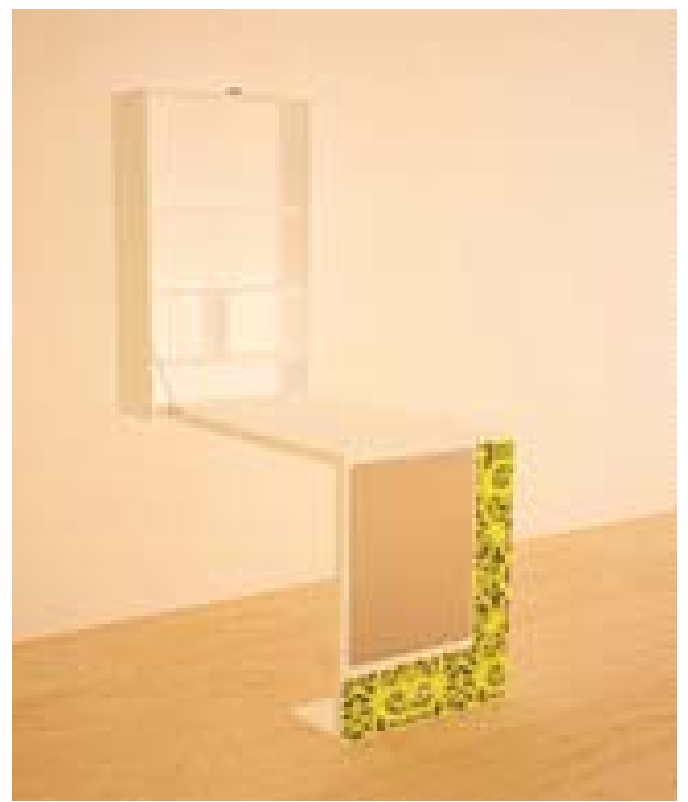

Gambar 4. Gambar presentasi

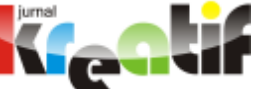

Vol. 3, No. 2, April 2016

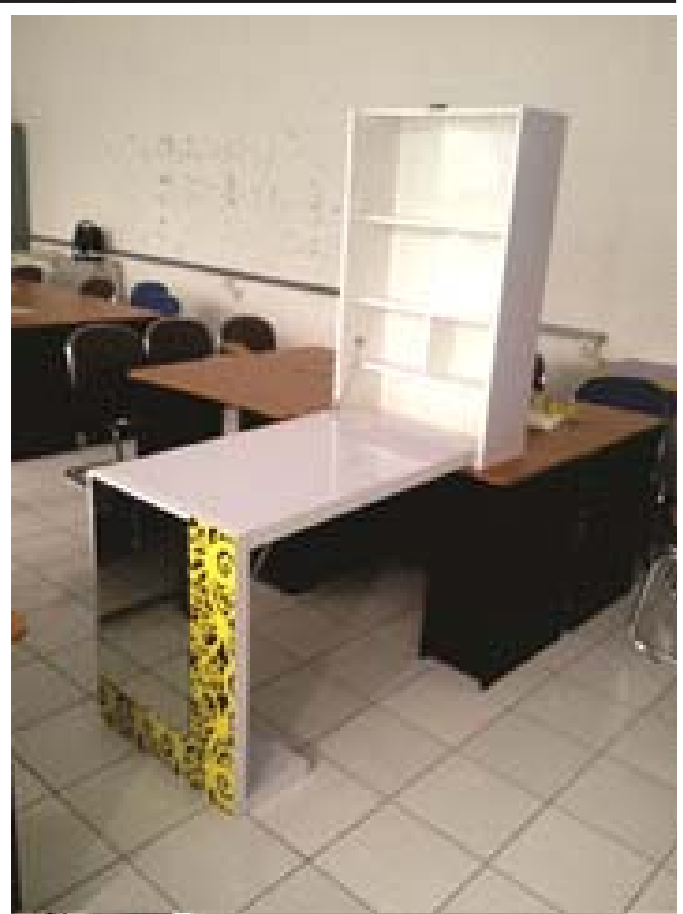

Gambar 5. Prototipe produk

\section{Kesimpulan}

Berdasarkan hasil dari perancangan “Desain Makan Lipat Minimalis", maka kesimpulan yang didapat adalah: Meja yang dihasilkan memiliki fungsi dan inovasi yang dapat memudahkan pengguna saat menggunakan meja kerja tersebut. Meja yang dihasilkan tidak memakan banyak tempat karena menempel didinding sehingga mengatasi keterbatasan lahan. Meja menggunakan material multriplek sehingga lebih kuat dan finishingnya menggunakan HPL sehingga meja yang dihasilkan lebih bagus. Bentuk meja yang menggunakan minimalis ditujukan untuk ruangan yang memiliki keterbatasan lahan.

Desain perancangan "Meja Makan Lipat Minimalis" ini kedepannya diharapkan dapat diterima dimasyarakat, dengan bentuk 
Roni H, Ismail, Desain Meja Makan Lipat Untuk Apartemen Pandan Wangi Tipe 21

yang lebih menarik, agar dapat menjadi

produk yang banyak diminati para

konsumen.Penelitian mengenai aktifitas

konsumen yang berkaitan dengan produk

yang dirancang juga dapat memberikan nilai

tambah produk tersebut karena kemungkinan

kebutuhan kosumen telah terpenuhi. Dalam

perancangan desain kali ini masih banyak

terdapat kesalahan dan kekurangan.Dalam

mendapatkan hasil yang maksimal mesti

adanya perbaikan pengembangan lebih

lanjut untuk kedepannya.Diharapkan agar

meja makan tersebut dapat lebih baik lagi

dari sebelumnya agar dapat diterima

dipasaran dan disukai para konsumen. 


\section{Daftar Rujukan}

Asti Griya (2014). Meja Makan Lipat, Efektif Atasi Lahan Sempit, 12 Maret, 2016. http:// majalahasri.com/meja-makan-lipat-efektif-atasi-lahan-sempit/

Deko, \& Haryo. (2014, Desember 31).Furni Wood Interior. Maret 12, 2015.CV. Akilla ConceptPerum Sukolilo Park Regency E 31 Surabayawww.Furniwoodinterior.com

Grandjean, E. (1986). Fitting the task to the man: An ergonomics approach. Philadelphia: Taylor \& Francis.

John Stefford, Guy McMurdo. (1983).”Woodwork Technology - Teknologi Kerja Kayu”. Alih Bahasa: Haroen. Jakarta: Penerbit Erlangga.

Khedanta.(2011). Jenis Engsel.28 Maret, 2015.https://khedanta.wordpress.com/2011/08/ 02/jenis-engsel/

Muhammad Suyanto. (2004). Smart In Entrepreneur : Belajar dari Kesuksesan Pengusaha Top Dunia, Penerbit ANDI Yogyakarta

Marizar, E.S. (2005). Designing Furniture. Yogyakarta: Penerbit Media Pressindo.

Manetsch dan Park(1979) dikutip dalam Eriyatno. 1999. "Ilmu Sistem: Meningkatkan Mutu dan Efektivitas Manajemen”. Jilid Satu. IPB Press, Bogor

Martono, Budi. (2008).Teknik Perkayuan Jilid 2. Jakarta: Penerbit Direktorat Pembinaan Sekolah Menengah Kejuruan.

Mitsubishi, A. (2006). Tripleks dan Multiplesk 13 Maret, 2016. http://

www.sonokelingwood.com/?p=329

Minima Interior. (2014.) Best Blogger Template. Maret20, 2016. http://

minimainterior.blogspot.co.id/

Nurmianto, E. (1991). Ergonomi: Konsep Dasar dan Aplikasinya (2rd ed). Surabaya:

Penerbit Guna Widya

Royan, F.M. (2007). Smart Launching New Product. Jakarta: Penerbit PT Elex Media Komputindo.

Philip Kotler dan Gary Amstrong(2015).Pengertian segmentasi pasar 13 Maret, 2016. http://www.ciputra-uceo.net/blog/2015/7/14/

Sulasmi Darmaprawira W.A, “Warna teori dan kreativitas penggunaannya” 2002:9-11 